\title{
$\dot{\nabla}_{\text {Nursing }}^{\text {Global Academic }}$
}

ARTIGO DE REVISÃO

\section{A atuação do socorrista leigo em caso de parada cardiorrespiratória em ambiente extra-hospitalar}

\author{
The role of lay rescuers in case of cardiopulmonary arrest in an extra-hospital environment
}

El papel de los socorristas legos en caso de parada cardiopulmonar en un entorno extrahospitalario

\author{
Thalisson Serrath de Carvalho ${ }^{1}$ \\ ORCID: 0000-0002-3806-7126 \\ Cláudio José de Souza ${ }^{1}$ \\ ORCID: 0000-0001-7866-039X \\ Pedro Ruiz Barbosa Nassar ${ }^{1}$ \\ ORCID: 0000-0002-9238-0518 \\ Aline Silva da Fonte Santa Rosa \\ de Oliveira² \\ ORCID: 0000-0002-4070-7436

\section{${ }^{1}$ Universidade Federal} \\ Fluminense. Rio de Janeiro, \\ Brasil. \\ ${ }^{2}$ Faculdade Bezerra de Araújo. Rio \\ de Janeiro, Brasil.
}

\section{Como citar este artigo:}

Carvalho TS, Souza CJ, Nassar PRB, Oliveira ASFSR. A atuação do socorrista leigo em caso de parada cardiorrespiratória em ambiente extra-hospitalar. Glob Acad Nurs. 2021;2(4):e201.

https://dx.doi.org/10.5935/26755602.20200201

\section{Autor correspondente:}

Thalisson Serrath de Carvalho

E-mail: thalissoncarvalho@id.uff.br

Editor Chefe: Caroliny dos Santos Guimarães da Fonseca

Editor Executivo: Kátia dos Santos Armada de Oliveira

Submissão: 21-10-2021

Aprovação: 26-11-2021

\section{Resumo}

Objetivou-se analisar as evidências sobre a atuação do leigo em casos de parada cardiorrespiratória extrahospitalar. Trata-se de revisão integrativa de literatura, de característica crítica e retrospectiva, com fontes de dados primários completos, publicados entre 2015 e 2020, nas seguintes bases de dados: MEDLINE, LILACS, BDENF, SciELO e o Google Scholar. As publicações incluídas no estudo foram 07 artigos. Os resultados encontrados evidenciaram que, o treinamento de leigos pode ser feito por uma conciliação entre autoaprendizagem e o ensino ministrado por instrutores com aulas práticas. Caso não haja um curso ou treinamento conduzido por instrutor, o chamado treinamento autodirigido é uma recomendação aceita para socorristas leigos, aulas por meio de vídeos podem direcionar ainda mais o aprendizado. Com mais pessoas treinadas, existe uma maior chance de uma delas presenciar um caso parada cardiorrespiratória extra-hospitalar e realizar a reanimação cardiopulmonar de qualidade. Ao analisar a atuação do leigo em casos de parada cardiorrespiratória extra-hospitalar, esta atuação quando realizada de acordo com os protocolos internacionais, proporcionará um atendimento precoce a vítima e aumentará a taxa de sobrevivência, servindo assim de alicerce para a assistência do serviço médico de emergência quando chegar ao local.

Descritores: Cardioversão Elétrica; Ensino; Parada Cardíaca; Parada Cardíaca Extra-Hospitalar; Tutoria.

\begin{abstract}
The aim was to analyze the evidence on the role of laypersons in cases of out-of-hospital cardiopulmonary arrest. This is an integrative literature review, with a critical and retrospective characteristic, with complete primary data sources, published between 2015 and 2020, in the following databases: MEDLINE, LILACS, BDENF, SciELO and Google Scholar. The publications included in the study were 07 articles. The results found showed that the training of lay people can be done through a balance between self-learning and teaching given by instructors with practical classes. If there is no instructor-led course or training, so-called selfdirected training is an accepted recommendation for lay rescuers, video classes can further drive learning. With more people trained, there is a greater chance that one of them will witness an out-of-hospital cardiopulmonary arrest case and perform quality cardiopulmonary resuscitation. When analyzing the layperson's performance in cases of out-of-hospital cardiopulmonary arrest, this action, when performed in accordance with international protocols, will provide early assistance to the victim and increase the survival rate, thus serving as a foundation for the assistance of the medical service of emergency when you get to the scene.
\end{abstract}

Descriptors: Electric Countershock; Teaching; Heart Arrest; Out-of-Hospital Cardiac Arrest; Mentoring.

\section{Resumén}

El objetivo fue analizar la evidencia sobre el papel de los profanos en los casos de parada cardiorrespiratoria extrahospitalaria. Se trata de una revisión de literatura integradora, de carácter crítico y retrospectivo, con fuentes primarias completas de datos, publicada entre 2015 y 2020, en las siguientes bases de datos: MEDLINE, LILACS, BDENF, SciELO y Google Scholar. Las publicaciones incluidas en el estudio fueron 07 artículos. Los resultados encontrados mostraron que la formación de los laicos se puede realizar a través de un equilibrio entre el autoaprendizaje y la docencia impartida por los instructores con clases prácticas. Si no hay un curso o capacitación dirigida por un instructor, la llamada capacitación autodirigida es una recomendación aceptada para los rescatistas legos, las clases de video pueden impulsar aún más el aprendizaje. Con más personas capacitadas, existe una mayor probabilidad de que una de ellas sea testigo de un caso de paro cardiopulmonar extrahospitalario y realice una reanimación cardiopulmonar de calidad. Al analizar el desempeño del laico en los casos de parada cardiopulmonar extrahospitalaria, esta acción, cuando se realiza de acuerdo con los protocolos internacionales, brindará atención temprana a la víctima y aumentará la tasa de supervivencia, sirviendo de base para la asistencia del médico. servicio de emergencia al llegar al lugar.

Descriptores: Cardioversión Eléctrica; Enseñanza; Paro Cardíaco; Paro Cardíaco Extrahospitalario; Tutoría. 


\section{Introdução}

A parada cardiorrespiratória (PCR) é considerada uma das principais emergências clínicas do mundo, tem como definição básica a cessação dos batimentos cardíacos e a perda da função respiratória, gerando consequentemente uma perda de consciência repentina. Nesse contexto, prejuízos fisiológicos irreparáveis podem ser gerados em um curto tempo caso não haja nenhum atendimento rápido, uma vez que, logo após os primeiros cinco minutos de PCR o paciente pode ter danos cerebrais irreversíveis ${ }^{1}$.

De acordo com a atualização da Diretriz de Ressuscitação Cardiopulmonar e Cuidados Cardiovasculares de Emergência da Sociedade Brasileira de Cardiologia (SBC) ${ }^{2}$, os dados publicados na literatura sobre a incidência de PCR no país são escassos. No entanto, a I Diretriz de Ressuscitação Cardiopulmonar e Cuidados Cardiovasculares de Emergência da SBC ${ }^{3}$, cita que cerca de 200.000 PCRs acontecem por ano no Brasil, sendo a metade em ambiente não hospitalar.

A parada cardiorrespiratória extra-hospitalar (PCREH) é considerada um problema de saúde pública. Nos Estados Unidos, aproximadamente 155.000 pessoas por ano são atendidas pelo serviço de emergência fora dos hospitais, apenas $8 \%$ dessas pessoas sobrevivem. No que se refere ao continente Europeu, por volta de 128.000 a 275.000 pessoas são vítimas de uma PCREH, cerca de $10 \%$ sobrevivem ${ }^{4}$. Mesmo com o desenvolvimento progressivo, um número inferior a $40 \%$ dos adultos em situação de PCR recebe Ressuscitação Cardiopulmonar (RCP) realizadas por leigos, menor ainda (cerca de 12\%) é a chance de uma vítima receber uma desfibrilação pelo Desfibrilador Externo Automático (DEA) antes do atendimento especializado chegar.

O leigo pode fazer o primeiro atendimento nessa situação emergencial, desde que seja adequadamente capacitado e informado. Um estudo sobre o conhecimento dos leigos a respeito do suporte básico de vida (SBV), realizado na cidade de Juiz de Fora no Estado de Minas Gerais e corroborado pela literatura nacional e internacional, constatou que o desempenho dos participantes da pesquisa foi baixo, até mesmo o desempenho de quem relatou ter tido contato com a temática anteriormente ${ }^{6}$.

Apesar de inúmeros estudos refletindo a importância do conhecimento dos primeiros socorros, ainda é uma temática pouco disseminada no Brasil. Em uma cena em que uma pessoa tenha um mal súbito em local público, o auxílio é feito por meio do sentimento de solidariedade e muitas vezes, sem técnica ou conhecimento para tal situação. Essa é uma ação que pode agravar o quadro de saúde da vítima?.

Mediante aos fatos apresentados emergiu a seguinte pergunta norteadora: Como deve ser a atuação do leigo em casos de parada cardiorrespiratória extrahospitalar? Que tem como objetivo analisar na literatura científica as evidências sobre a atuação do leigo em casos de parada cardiorrespiratória extra-hospitalar.

\section{Metodologia}

Trata-se de uma Revisão Integrativa da Literatura (RIL) por esta viabilizar a sistematização do conhecimento científico aproximando aquele que pesquisa da problemática que deseja avaliar, traçando a evolução do tema ao longo do tempo e, com isso, visualizando possíveis oportunidades de pesquisa ${ }^{8}$.

Foram seguidas as seis etapas intrínsecas a este método: Identificação do tema e seleção da questão norteadora, Estabelecimentos dos critérios de inclusão e exclusão, Identificação dos estudos pré-selecionados e selecionados, Categorização dos estudos selecionados, Análise e interpretação dos resultados e Apresentação da síntese do conhecimento ${ }^{8}$.

A revisão integrativa foi desenvolvida previamente com a identificação do tema de pesquisa que é a "atuação do leigo na parada cardiorrespiratória extra-hospitalar". Posteriormente, foram definidos os problemas de pesquisa, sendo estes o impacto da atuação em relação ao melhor prognóstico em relação ao evento de PCR e a atuação inicial deste indivíduo em uma emergência. A partir dessa definição, elaborou-se a questão norteadora do estudo pautada na estratégia PICo, que apresenta como questão para a sua formulação o prognóstico ou predição, em que o " $P$ " aponta a população, paciente (idade, raça, status, de saúde) ou problema, o "I" demonstra o interesse e o "Co" contexto

Diante do exposto, a questão norteadora deste estudo, foram pautadas na estratégia PICo, sendo esta: Como deve ser a atuação do leigo em casos de parada cardiorrespiratória extra-hospitalar?

Figura 1. Diagrama ilustrativo do processo de elaboração da questão norteadora. Rio de Janeiro, RJ, Brasil, 2021

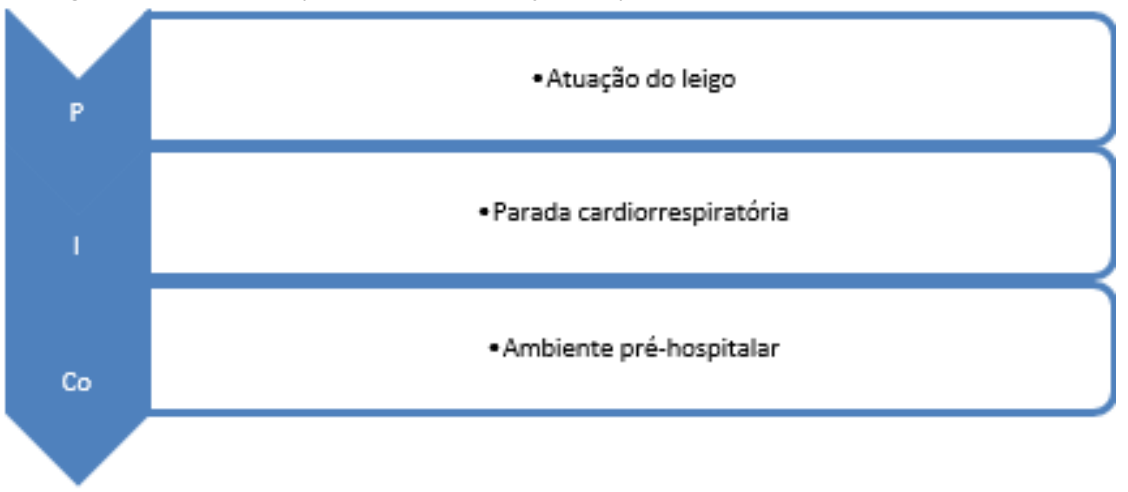


A Figura 1 acima, mostra todo o processo de elaboração da questão norteadora da pesquisa.

Para a realização da pesquisa foi utilizada a Biblioteca Virtual de Saúde e suas respectivas bases de dados: Medical Literature Analysis and Retrieval System Online (MEDLINE), Bases de Dados da Enfermagem (BDENF) e a Literatura Latino-americana e do Caribe em Ciências da Saúde (LILACS), foi consultado também a Scientific Electronic Library Online (SciELO), e com o intuito de localizar o maior quantitativo de publicações também foi utilizado Literatura Cinzenta com busca no Google Acadêmico. O período de realização das buscas ocorreu de janeiro até final de agosto de 2021.
Para a realização das buscas foram utilizados os descritores cadastrados no Portal de Descritores das Ciências da Saúde (DeCS): "parada cardíaca", "parada cardíaca extra-hospitalar", "cardioversão elétrica" e os seus equivalentes nos idiomas inglês e espanhol. A palavra "leigo" foi utilizada de forma separada, na qualidade de palavrachave, por não se encontrar cadastrada no DeCS até a realização do trabalho e cruzada com os termos "parada cardiorrespiratória" e "desfibrilador" para adequação das produções encontradas a temática da pesquisa, utilizando o operador booleano " $A N D$ ". Com base na estratégia de busca pode-se evidenciar o número de produções associadas a temática conforme descrito no fluxograma abaixo:

Figura 2. Fluxograma ilustrativo do caminhar metodológico para a identificação dos estudos pré-selecionados e seleção dos estudos a serem incluídos na revisão adaptado do PRISMA. Rio de Janeiro, RJ, Brasil, 2021

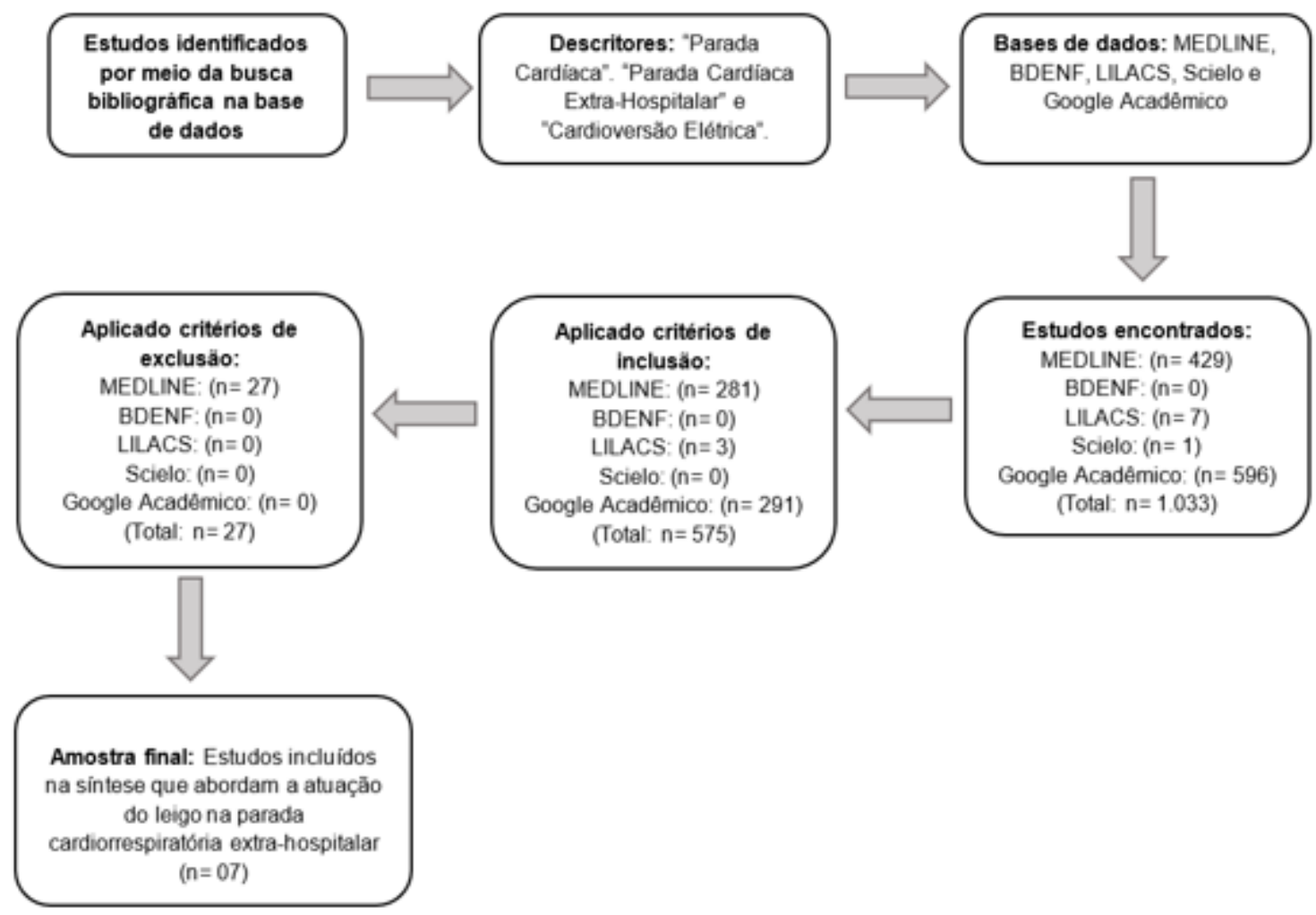

Como critérios de inclusão: artigos disponibilizados na íntegra, nas bases de dados selecionadas, que apresentam aderência à temática nos idiomas português, espanhol e inglês, publicados entre os anos de 2015 e 2020, com vistas a identificar as evidências da temática em questão publicada nos últimos 05 (cinco) anos, visto que o Guideline referente às diretrizes da RCP foi revisto em 2015 e 2020.

Foram excluídos estudos sem disponibilidade do texto completo e que não são compatíveis no contexto da temática a ser abordada, bem como, estudos cujo link de acesso no momento da coleta encontra-se indisponível. Para incluir os estudos, foi realizada a leitura dos títulos e resumos de cada publicação para averiguar harmonia com a pergunta norteadora. Se ocorreu algum tipo de dúvida no que se refere à inclusão ou exclusão de estudo, foi realizada a leitura na íntegra para diminuir o risco de prejuízo ao perder publicações relevantes para o estudo.

A Figura 2 exposta acima ilustra o caminhar metodológico para a identificação dos estudos préselecionados e seleção dos estudos a serem incluídos na revisão.

A análise dos dados ocorreu de forma criteriosa, mediante a relação das temáticas abordadas pelos artigos selecionados, uma vez que, o objetivo deste estudo se propõe analisar a atuação do socorrista leigo em caso de parada cardiorrespiratória em ambiente extra-hospitalar. Diante do exposto, os dados extraídos foram descritos e organizados em um quadro com informações referentes a: Número da publicação; Título do artigo; Os autores das publicações; O nome do periódico e a data; Base de dados; País e Idioma e os Principais achados da pesquisa, conforme descrito no Quadro 1. 
Quadro 1. Lista de artigos selecionados nas bases de dados. Rio de Janeiro, RJ, Brasil, 2021

\begin{tabular}{|c|c|c|c|c|c|}
\hline Título & Autores & Periódico/Data & Base de dados & $\begin{array}{l}\text { País/ } \\
\text { Idioma }\end{array}$ & Principais Achados \\
\hline $\begin{array}{l}\text { Motivation, } \\
\text { challenges } \\
\text { and realities of } \\
\text { volunteer } \\
\text { community } \\
\text { cardiac arrest } \\
\text { response: a } \\
\text { qualitative } \\
\text { study of 'lay' } \\
\text { community } \\
\text { first } \\
\text { responders }\end{array}$ & $\begin{array}{l}\text { BARRY, T.; GUERIN, } \\
\text { S.; BURY, G. }{ }^{9}\end{array}$ & $\begin{array}{l}\text { The BMJ, Jun, } \\
2019\end{array}$ & MEDLINE & $\begin{array}{l}\text { Irlanda/ } \\
\text { Inglês }\end{array}$ & $\begin{array}{l}\text { A implantação de um } \\
\text { serviço de atendimento } \\
\text { realizado por atendentes } \\
\text { leigos locais de uma } \\
\text { comunidade é um alicerce } \\
\text { para a realização da RCP e } \\
\text { da desfibrilação precoce e } \\
\text { de qualidade antes da } \\
\text { chegada do serviço de } \\
\text { emergência, podendo gerar } \\
\text { maiores taxas de } \\
\text { sobrevivências. }\end{array}$ \\
\hline $\begin{array}{c}\text { Out-of- } \\
\text { hospital } \\
\text { cardiac arrest } \\
\text { survival in } \\
\text { international } \\
\text { airports }\end{array}$ & $\begin{array}{c}\text { MASTERSON, S.; } \\
\text { McNALLY, B.; } \\
\text { CULLINAN, J. et al. }{ }^{10}\end{array}$ & $\begin{array}{l}\text { Resuscitation, } \\
\text { Mar, } 2018\end{array}$ & MEDLINE & $\begin{array}{l}\text { Suécia/ } \\
\text { Inglês }\end{array}$ & $\begin{array}{l}\text { A ocorrência de PCREH em } \\
\text { aeroportos internacionais é } \\
\text { relativamente alta e a } \\
\text { chance de um desfecho } \\
\text { positivo é maior do que na } \\
\text { maioria dos locais onde esse } \\
\text { evento acontece. O estudo } \\
\text { demonstrou que em 59\% } \\
\text { dos casos o espectador } \\
\text { realizou o choque, sendo } \\
\text { que } 42 \% \text { dos pacientes } \\
\text { estavam em um ritmo } \\
\text { chocável no momento e um } \\
\text { terço das vítimas } \\
\text { sobreviveram. Sugerindo a } \\
\text { importância da } \\
\text { disponibilização de DEA de } \\
\text { acesso público em locais } \\
\text { estrategicamente } \\
\text { apropriados como um } \\
\text { aeroporto internacional. }\end{array}$ \\
\hline $\begin{array}{l}\text { Out-of- } \\
\text { hospital } \\
\text { cardiac arrest: } \\
\text { Probability of } \\
\text { bystander } \\
\text { defibrillation } \\
\text { relative to } \\
\text { distance to } \\
\text { nearest } \\
\text { automated } \\
\text { external } \\
\text { defibrillator }\end{array}$ & $\begin{array}{l}\text { SONDERGAARD, K. B.; } \\
\text { HANSEN, S.M.; } \\
\text { PALLISGAARD, J.L. et } \\
\text { al. }^{11}\end{array}$ & $\begin{array}{l}\text { Resuscitation, } \\
\text { Nov, } 2017\end{array}$ & MEDLINE & $\begin{array}{l}\text { Dinamarca/ } \\
\text { Inglês }\end{array}$ & $\begin{array}{l}\text { Apesar das recomendações } \\
\text { da American Heart } \\
\text { Association e da European } \\
\text { Resuscittation sobre a } \\
\text { importância da } \\
\text { disponibilização de DEA em } \\
\text { locais de acesso público, e a } \\
\text { grande aderência dessas } \\
\text { recomendações pelos } \\
\text { países, apenas 2-4\% das } \\
\text { vítimas foram desfibriladas } \\
\text { por um transeunte. O } \\
\text { trabalho cita alguns desses } \\
\text { empecilhos como a grande } \\
\text { distância entre um DEA e a } \\
\text { vítima, a diferença de uma } \\
\text { PCREH em uma residência e } \\
\text { em uma via pública, locais } \\
\text { que disponibilizam DEA } \\
\text { fechados e o } \\
\text { desconhecimento da } \\
\text { população para usar o } \\
\text { aparelho. }\end{array}$ \\
\hline $\begin{array}{l}\text { Minnesota } \\
\text { Heart Safe } \\
\text { Communities: } \\
\text { Are } \\
\text { community- } \\
\text { based } \\
\text { initiatives } \\
\text { increasing pre- } \\
\text { ambulance } \\
\text { CPR and AED } \\
\text { use? }\end{array}$ & $\begin{array}{c}\text { BOLAND, L. L; } \\
\text { FORMANEK, M.B.; } \\
\text { HARKINS, K.K. et al. }{ }^{12}\end{array}$ & $\begin{array}{l}\text { Resuscitation, } \\
\text { Jul, } 2017\end{array}$ & MEDLINE & $\begin{array}{l}\text { EUA/ } \\
\text { Inglês }\end{array}$ & $\begin{array}{l}\text { O programa Minnesota } \\
\text { Heart Safe Communities foi } \\
\text { criado para incentivar e } \\
\text { conscientizar a população } \\
\text { sobre o atendimento de } \\
\text { uma PCREH. Antes da } \\
\text { criação do programa, 83\% } \\
\text { das vítimas receberam RCP } \\
\text { e o uso do DEA foi de } 63 \% \\
\text { antes da chegada do serviço } \\
\text { médico de emergência. }\end{array}$ \\
\hline $\begin{array}{l}\text { Cardiopulmon } \\
\text { ary }\end{array}$ & $\begin{array}{l}\text { PARK, Y. M.; SHIN, } \\
\text { S.D.; LEE, Y. J. et al. }{ }^{13}\end{array}$ & $\begin{array}{l}\text { Resuscitation, } \\
\text { Jun, } 2017\end{array}$ & MEDLINE & $\begin{array}{l}\text { Coréia do } \\
\text { Sul/ }\end{array}$ & $\begin{array}{l}\text { O estudo foi caracterizado } \\
\text { na divisão em um grupo }\end{array}$ \\
\hline
\end{tabular}




\begin{tabular}{|c|c|c|c|c|c|}
\hline $\begin{array}{l}\text { resuscitation } \\
\text { by trained } \\
\text { responders } \\
\text { versus lay } \\
\text { persons and } \\
\text { outcomes of } \\
\text { out-of-hospital } \\
\text { cardiac arrest: } \\
\text { A community } \\
\text { observational } \\
\text { study }\end{array}$ & & & & Inglês & $\begin{array}{l}\text { específico da população que } \\
\text { tem a maior chance de } \\
\text { testemunhar uma PCREH } \\
\text { como bombeiros, policiais, } \\
\text { motoristas de transporte } \\
\text { público, professores, } \\
\text { instrutores esportivos e } \\
\text { salva-vidas, o outro grupo é } \\
\text { formado pela comunidade } \\
\text { leiga em geral. Foram } \\
\text { analisados } 6,475 \text { eventos de } \\
\text { PCREH e o grupo com as } \\
\text { pessoas mais prováveis em } \\
\text { presenciar esse evento } \\
\text { testemunharam uma baixa } \\
\text { incidência de PCREH. No } \\
\text { entanto, ao comparar com o } \\
\text { grupo de leigos, obtiveram } \\
\text { taxas mais elevadas de } \\
\text { realização de RCP e } \\
\text { desfibrilação, o que resultou } \\
\text { em melhores resultados. }\end{array}$ \\
\hline $\begin{array}{l}\text { Bystander } \\
\text { Defibrillation } \\
\text { for Out-of- } \\
\text { Hospital } \\
\text { Cardiac Arrest } \\
\text { in Public vs } \\
\text { Residential } \\
\text { Locations }\end{array}$ & $\begin{array}{l}\text { HANSEN, S. M.; } \\
\text { HANSEN, C.M.; } \\
\text { FOLKE, F. et al. }{ }^{14}\end{array}$ & $\begin{array}{c}\text { JAMA } \\
\text { Cardiology, } \\
\text { Mar, } 2017\end{array}$ & MEDLINE & $\begin{array}{c}\text { Dinamarca/ } \\
\text { Inglês }\end{array}$ & $\begin{array}{c}\text { A American Heart } \\
\text { Association e o European } \\
\text { Resuscitation Council } \\
\text { recomendam a ampla } \\
\text { distribuição do DEA em } \\
\text { muitos países. Foram } \\
\text { incluídos no estudo } 18.688 \\
\text { pacientes que tiveram um } \\
\text { mal súbito entre } 2001 \text { e } \\
2012 \text {, sendo } 67,8 \% \text { homens } \\
\text { e } 32,2 \% \text { mulheres, } 4.783 \\
\text { casos de PCREH ocorrem em } \\
\text { ambientes públicos e } 13.905 \\
\text { em locais residenciais. Nos } \\
\text { locais residenciais } \\
\text { aumentou de } 0,0 \% \text { para } \\
25 \% \text { no decorrer dos anos. } \\
\text { Disponibilizar o aparelho, } \\
\text { educar os leigos sobre a RCP } \\
\text { e um aumento da } \\
\text { desfibrilação foram } \\
\text { indicativos para um melhor } \\
\text { prognóstico de sobrevida } \\
\text { das vítimas. }\end{array}$ \\
\hline $\begin{array}{c}\text { The role of } \\
\text { bystanders, } \\
\text { first } \\
\text { responders, } \\
\text { and } \\
\text { emergency } \\
\text { medical } \\
\text { service } \\
\text { providers in } \\
\text { timely } \\
\text { defibrillation } \\
\text { and related } \\
\text { outcomes } \\
\text { after out-of- } \\
\text { hospital } \\
\text { cardiac arrest: } \\
\text { Results from a } \\
\text { statewide } \\
\text { registry }\end{array}$ & $\begin{array}{l}\text { HANSEN, C. M.; } \\
\text { KRAGHOLM, K.; } \\
\text { GRANGER, C.B. et } \\
\text { al. }^{15}\end{array}$ & $\begin{array}{l}\text { Resuscitation, } \\
\text { Sep, } 2015\end{array}$ & MEDLINE & $\begin{array}{l}\text { EUA/ } \\
\text { Inglês }\end{array}$ & $\begin{array}{l}\text { O trabalho faz uma } \\
\text { comparação entre o } \\
\text { atendimento de uma PCREH } \\
\text { por espectadores, primeiros } \\
\text { respondentes e } \\
\text { profissionais do serviço de } \\
\text { saúde. No contexto geral, os } \\
\text { espectadores iniciaram a } \\
\text { RCP em mais da metade dos } \\
\text { casos. }\end{array}$ \\
\hline
\end{tabular}

A seguir, foi possível analisar as distribuições dos artigos eleitos de acordo com o ano de publicação. Foram: $(n=1 ; 14,28 \%)$ no ano de 2015; $(n=3 ; 42,85 \%)$ no ano de 2017; $(n=2 ; 28,57 \%)$ no ano de 2018; $(n=1 ; 14,28 \%)$ no ano de 2019.
Em relação aos periódicos selecionados, $(n=5$; $71,42 \%)$ são do Jornal Ressuscitation; $(n=1 ; 14,28 \%)$ da The BMJ e $(n=1 ; 14,28 \%)$ da JAMA Cardiology. Sobre o idioma das publicações, $(n=07 ; 100 \%)$ dos artigos selecionados foram publicados em inglês. Foi possível observar os países de origem das pesquisas realizadas, $(n=2 ; 28,58 \%)$ da 
Dinamarca; $(n=2 ; 28,58 \%)$ dos Estados Unidos; $(n=1 ; 14,28 \%)$ da Coréia do Sul; $(n=1 ; 14,28 \%)$ da Irlanda e $(n=1 ; 14,28 \%)$ da Suécia.

Mediante aos dados analisados pela análise de conteúdo de Bardin foi possível apontar uma categoria temática o qual será analisado e discutido a seguir ${ }^{16}$.

\section{Resultados}

\section{Atuação do socorrista leigo na parada cardiorrespiratória em ambiente extra-hospitalar}

É esperado que uma pessoa comum presencie frequentemente mais episódios de parada cardiorrespiratória em locais fora de hospitais do que um profissional de saúde. Em ambientes onde socorristas leigos treinados conseguem alcançar velozmente uma vítima, são maiores as taxas de sobrevida após o acontecimento. $O$ que pode motivar um leigo a socorrer outra pessoa é algum tipo de experiência anterior, como sentir-se preparado, alguma doença na família ou até mesmo uma forma de retribuir esses saberes apreendidos para a comunidade onde vive $e^{9,11,13}$.

No estudo de Hansen e colaboradores ${ }^{15}$, poucos pacientes obtiveram desfibrilação precoce após o reconhecimento da parada cardiorrespiratória, o qual considera-se o momento de maior benefício do choque. Mesmo com transeuntes iniciando a ressuscitação cardiopulmonar, apenas em $10 \%$ do tempo eles realizaram a desfibrilação. Em outros estudos, cita-se que nos Estados Unidos a maioria das pessoas que sofrem um mal súbito em vias públicas tem uma probabilidade pequena de receber uma RCP, em relação ao uso do DEA, o seu uso concomitantemente com a RCP ocorre em apenas $10 \%$ dos atendimentos realizados por leigos ${ }^{12}$.

Em lugares onde geralmente se tenha um quantitativo maior que 1.500 transeuntes por dia como por exemplos: aeroportos; estádios de futebol; shoppings; praias. No qual há pessoas com vários tipos de formações e costumes, é esperado numa sociedade onde se prima pela utilização dos primeiros socorros por leigos que seja encurtado o momento desde a parada cardiorrespiratória e o primeiro atendimento a uma vítima. Corroborando com estas suposições os estudos, indicam em pesquisa que em 70 aeroportos internacionais localizados em 9 países e obteve que $32 \%$ de todos os pacientes atendidos sobreviveram e tiveram alta hospitalar. Além disso, cita que há uma pequena diferença probabilística de sobrevivência em vítimas testemunhadas por espectadores ou pelo serviço médico de emergência, o que realmente importa é a rápida desfibrilação, independentemente de quem a realizar ${ }^{10}$.

Outro fator que influencia de forma negativa os primeiros socorros e consequentemente a desfibrilação precoce são eventos que acontecem em domicílios. Um estudo nacional realizado na Dinamarca constatou que houve um aumento no uso do DEA de 1,2\% em 2001 para 15,3\% em 2012 quando a PCR acontecia em ambiente público, já em locais residenciais, a desfibrilação por um espectador permaneceu inalterada. Os estudos apresentados versam sobre as taxas muito baixas de desfibrilação em áreas privadas, aponta ainda que os porteiros são potenciais candidatos para realizar cursos e treinamentos para serem os principais socorristas em locais privados $^{13,14}$.

Apesar da grande importância de o leigo prestar o primeiro socorro em uma vítima de PCR antes da chegada do serviço médico de emergência, muitas das vezes esse atendimento não é realizado. Acredita-se que, a não atuação deste indivíduo leigo em um caso de PCR seja por falta de qualificação em um primeiro momento (cursos de primeiros socorros), em segundo, pode-se pensar no despreparo psicológico até desconhecimento de quais manobras deverão ser feitas. E, a cada minuto sem nenhum atendimento correto, o prognóstico de sobrevida da vítima diminui drasticamente.

Vale ressaltar, uma manobra realizada sem um aparato técnico-científico ao invés de ajudar a vítima a sair deste evento de PCR, pode contribuir para outras situações o qual o prognóstico pode ser desfavorável. Tais situações aqui no Brasil, podem ser evidenciadas durante as Olimpíadas de 2016 onde vários vídeos foram compartilhados nas redes sociais de pessoas despreparadas realizando manobras que não condizem o que é preconizado pelas associações médicas de emergência.

\section{Discussão}

De acordo com o Art. 135 do Código Penal Brasileiro: "Deixar de prestar assistência, quando possível fazê-lo sem risco pessoal, à criança abandonada ou extraviada, ou à pessoa inválida ou ferida, ao desamparo ou em grave e iminente perigo; ou não pedir, nesses casos, o socorro da autoridade pública", com pena de detenção de um a seis meses, ou multa. Podendo a pena ser aumentada de metade, se a omissão resultar em lesão corporal de natureza grave, e triplicada, se resultar em morte ${ }^{17}$.

Define-se leigo como aquele que não tem conhecimento sobre determinado assunto; que expressa certa ignorância acerca de alguma coisa; desconhecedor. Os trabalhos realizados sobre o conhecimento da população leiga a respeito do SBV são escassos na literatura brasileira $^{6,18}$.

Mesmo que as diretrizes da AHA recomendem uma inicialização rápida de RCP em uma PCR presumida, uma quantidade menor que $40 \%$ dos casos de PCREH em adultos tem alguma manobra de RCP realizada por um leigo, uma taxa menor ainda, $12 \%$ das vítimas foram desfibriladas por um DEA. O treinamento pode ser por uma combinação de autoaprendizagem e o ensino realizado por instrutores com o treinamento prático. Outra forma de ensinar um leigo é por meio da gamificação e de realidade virtual ${ }^{5}$.

A Cruz Vermelha foi criada por Henry Dunant em 1863 , desde o seu início teve como princípio a neutralidade e atividades humanitárias. No Brasil, teve como ponto de partida o ano de 1908 e desde 1910 começou a formação de recursos humanos em enfermagem e destaca-se com o ensino de primeiros socorros para leigos ${ }^{19}$.

O treinamento de leigos pode ser feito por uma conciliação entre autoaprendizagem e o ensino ministrado por instrutores com aulas práticas. Caso não haja um curso ou treinamento conduzido por instrutor, o chamado 
treinamento autodirigido é uma recomendação aceita para socorristas leigos, aulas por meio de vídeos podem direcionar ainda mais o aprendizado. Com mais pessoas treinadas, existe uma maior chance de uma delas presenciar um caso de PCREH e realizar a RCP de qualidade ${ }^{5}$.

O termo "simulação in situ" diz respeito aos treinamentos feitos em locais reais e mais propícios para o atendimento de uma vítima. É recomendável que sempre que possível tenham treinamentos sobre RCP nessas condições. A literatura atual comprova que a atuação in situ proporciona uma vivência diferente dos treinamentos convencionais e trazem resultados positivos para a aprendizagem ${ }^{5}$.

O uso da tecnologia é um ponto relevante e atual para o ensino e aprendizado do SBV. Estudos demonstram que a gamificação e a realidade virtual podem gerar vantagens para os participantes como uma melhora na aquisição de conhecimento, conservação de conhecimentos anteriores e aptidão em $\mathrm{RCP}^{5}$.

\section{Considerações Finais}

A pesquisa teve como objetivo analisar a produção científica acerca da atuação do leigo em casos de parada cardiorrespiratória extra-hospitalar, constata-se que o objetivo geral foi atendido porque efetivamente o trabalho conseguiu analisar as produções científicas de países totalmente diferentes e ao mesmo tempo trazer evidências de que este tipo de educação em saúde pode salvar vidas, o que foi evidenciado principalmente em países desenvolvidos.

Dessa forma, é preciso inserir na educação de base aulas teóricas e práticas voltadas para a temática da PCR e RCP em ambientes extra-hospitalares. É importante fazer com que as crianças e adolescentes semeiem o conhecimento em suas residências e comunidades e estejam preparadas para agir se necessário.

Sendo assim, espera-se que este estudo possa contribuir para a realização de mais pesquisa neste campo de conhecimento, visto que, foi possível identificar que em vários países há uma carência de pessoas com conhecimento para agir nesse tipo emergência. Ademais, acredita-se que as medidas educacionais sobre a temática abordada neste trabalho contribuirão para um aumento circunstancial das tentativas de reanimações realizadas por leigos, consequentemente em um aumento da taxa de sobrevida de vítimas de PCREH e terá como reflexo a diminuição da carência de pessoas qualificadas na sociedade. Além disso, é possível afirmar que capacitar novas pessoas é mais um campo de atuação para o profissional enfermeiro, principalmente pela sua formação abrangente e voltada para o ensino.

A principal limitação para desenvolver a pesquisa foi a incipiência de trabalhos relacionados ao tema no momento da busca, principalmente desenvolvidos no cenário Brasileiro. Sendo assim, a presente pesquisa aponta a necessidade de estudo nesta área de conhecimento.

\section{Referências}

1. Espíndola MCM, Espíndola MMM, Moura LTR, Lacerda LCA. Parada cardiorrespiratória: conhecimento dos profissionais de enfermagem em uma unidade de terapia intensiva. Revista de enfermagem UFPE On-line [Internet]. 2017 [acesso em 14 jan 2021];11(7): 2773-2778. Disponível em: https://periodicos.ufpe.br/revistas/revistaenfermagem/article/viewFile/23452/19162

2. Bernoche C, Timerman S, Polastri TF, Giannetti NS, Siqueira AWS, Piscopo A et al. Atualização da Diretriz de Ressuscitação Cardiopulmonar e Cuidados de Emergência da Sociedade Brasileira de Cardiologia - 2019. Arq Bras Cardiol. 2019;113(3):449-663. DOI: $10.5935 / a b c .20190203$

3. Gonzalez MM, Timerman S, Oliveira RG, Polastri TF, Dallan LAP, Araújo S, et al. I Guideline for Cardiopulmonary Resuscitation and Emergency Cardiovascular Care - Brazilian Society of Cardiology: Executive Summary. Arq Bras Cardiol 2013;100(2):105-13. DOI: $10.5935 / a b c .20130022$

4. Brady WJ, Mattu A, Slovis CM. Lay Responder Care for an Adult with Out-of-Hospital Cardiac Arrest. N Engl J Med. 2019;381(23):2242-2251. DOI: 10.1056/NEJMra1802529

5. American Heart Association (AHA). Destaques da American Heart Association 2020 [Internet]. Dallas (TX): AHA; 2020 [acesso em 28 abr 2021]. Disponível em: https://cpr.heart.org/-/media/cpr-files/cpr-guidelinesfiles/highlights/hghlghts_2020eccguidelines_portuguese.pdf

6. Chehuen Neto JA, Brum IV, Pereira DR, Santos LG, Moraes SL, Ferreira RE. Basic Life Support Knowledge and Interest among Laypeople. Int. j. cardiovasc. sci. (Impr.). 2016;29(6):443-452.DOI: 10.5935/2359-4802.20160064

7. Pereira KC, Paulino JR, Saltarelli RMF, Carvalho AMP, Santos RB, Silveira TVL, et al. A construção de conhecimentos sobre prevenção de acidentes e primeiros socorros por parte do público leigo. Revista de Enfermagem do Centro Oeste Mineiro. 2015;5(1):1478-1485. DOI: 10.19175/recom.v0i0.456

8. Cunha PLP, Alves PF, Cunha SC. Manual Revisão Bibliográfica Sistemática Integrativa: A pesquisa baseada em evidências [Internet]. Anima: Educação; 2014 [acesso em 28 abr 2021]. Disponível em: http://biblioteca.cofen.gov.br/wpcontent/uploads/2019/06/manual_revisao_bibliografica-sistematica-integrativa.pdf

9. Barry T, Guerin S, Bury G. Motivation, challenges and realities of volunteer community cardiac arrest response: a qualitative study of 'lay' community first responders. BMJ Open. 2019;5;9(8):e029015. DOI: 10.1136/bmjopen-2019-029015

10. Masterson S, McNally B, Cullinan J, Vellano K, Escutnaire J, Fitzpatrick D, et al. Out-of-hospital cardiac arrest survival in international airports. Resuscitation. 2018;127:58-62. DOI: 10.1016/j.resuscitation.2018.03.024

11. Sondergaard KB, Hansen SM, Pallisgaard JL, Gerds TA, Wissenberg M, Karlsson L, et al. Out-of-hospital cardiac arrest: probability of bystander defibrillation relative to distance to nearest automated external defibrillator. Resuscitation. 2018;124:138-44. DOI: 10.1016/j.resuscitation.2017.11.067 
12. Boland LL, Formanek Mb, Harkins KK, Frazee CL, Kamrud JW, Stevens AC, et al. Minnesota Heart Safe Communities: Are community-based initiatives increasing pre-ambulance CPR and AED use? Ressucitation. 2017;119:33-36. DOI: 10.1016/j.resuscitation.2017.07.031

13. Park YM, Shin SD, Lee YJ, Song KJ, Ro YS, Ahn KO. Cardiopulmonary resuscitation by trained responders versus lay persons and outcomes of out-of-hospital cardiac arrest: A community observational study. Resuscitation. 2017;118:55-62. DOI: 10.1016/j.resuscitation.2017.06.024

14. Hansen SM, Hansen CM, Folke F, Rajan S, Kragholm K, Ejlskov L, et al. Bystander Defibrillation for Out-of-Hospital Cardiac Arrest in Public vs Residential Locations. JAMA Cardiol. 2017;2(5):507-514. DOI: 10.1001/jamacardio.2017.0008

15. Malta Hansen C, Kragholm K, Pearson DA, Tyson C, Monk L, Myers B, et al. Association of Bystander and First-Responder Intervention With Survival After Out-of-Hospital Cardiac Arrest in North Carolina, 2010-2013. JAMA. 2015;314(3):255-64. DOI: 10.1001/jama.2015.7938

16. Bardin L. Análise de conteúdo. São Paulo: Edições70; 2012.

17. Brasil. Decreto Lei n.o 2848, de 7 de dezembro de 1940. Código Penal [Internet]. Brasília (DF): CP; 1940 [acesso em 07 jun 2021 ]. Disponível em: http://www.planalto.gov.br/ccivil_03/decreto-lei/del2848compilado.htm

18. Dicionário Online de Português (Dicio). Significado de leigo [Internet]. 2018 [acesso em 07 jun 2021 ]. Disponível em: https://www.dicio.com.br/leigo

19. Mecone MCC, Freitas GF, Bonini BB. Formação em Enfermagem na Cruz Vermelha Brasileira na década de 1940: uma abordagem Foucaultiana. Rev. esc. enferm. USP. 2015; 49(spe2):60-67. DOI: 10.1590/S0080-623420150000800009 